\title{
Can animal performance be predicted from short-term grazing processes?
}

\author{
P. C. F. Carvalho ${ }^{\mathrm{A}} \mathrm{E}$, C. Bremm ${ }^{\mathrm{B}}$, J. C. Mezzalira ${ }^{\mathrm{A}}$, L. Fonseca ${ }^{\mathrm{A}}$, J. K. da Trindade ${ }^{\mathrm{B}}$, \\ O. J. F. Bonnet ${ }^{\mathrm{A}}$, M. Tischler ${ }^{\mathrm{A}}$, T. C. M. Genro ${ }^{\mathrm{C}}$, C. Nabinger $^{\mathrm{A}}$ and E. A. Laca ${ }^{\mathrm{D}}$ \\ ${ }^{A}$ Grazing Ecology Research Group, Federal University of Rio Grande do Sul, Porto Alegre, RS 91540-000, Brazil. \\ ${ }^{B}$ Agricultural and Livestock Research Foundation, Porto Alegre, RS 90130-060, Brazil. \\ CEmbrapa Southern Region Animal Husbandry, Bagé, RS 96401-970, Brazil. \\ DPlant Science Department, University of California, One Shields Avenue, Davis, CA 95616, USA. \\ ${ }^{\mathrm{E}}$ Corresponding author. Email: paulocfc@ufrgs.br
}

\begin{abstract}
Despite all the biotic and abiotic factors affecting foraging by ruminants, there is a common and fundamental process, which is bite gathering. We hypothesised that because the mechanics of bite formation dominate the foraging process, changes in short-term bite mass are reflected in longer-term animal performance across a wide range of sward conditions. We focus at the meal level of foraging, using experiments in which the effect of abiotic factors and digestive constrains are minimised, making intake rate the main currency. We estimated bite mass across a wide range of structural challenges to large-herbivore foraging in a long-term experiment with heterogeneous native grasslands. A conceptual model was developed for average daily gain, where energy gain and energy costs were proximate causal variables. Energy gain was a function of diet quality and components of daily intake rate, where bite mass was the main component estimated. In turn, components of intake rate were determined by sward structure and bodyweight. Energy costs were a function of bodyweight and abiotic conditions. Finally, sward structure, bodyweight and abiotic conditions were determined by experimental treatments, seasons and years. Then, the conceptual model was translated into statistical models that included variables measured or estimated, and coefficients representing all links in the conceptual model. Weight gain was a function of bite mass, forage characteristics, and animal and abiotic conditions. Models were set up to test whether forage and stocking conditions affected monthly gain beyond the effects through bite mass, after correcting for abiotic factors. Forage mass, height and disappearance did help predict monthly gain after bite mass was included in the model, which supported our hypothesis. However, stocking treatments and season had significant effects not incorporated in bite mass. Although the model explained $77.9 \%$ of liveweight gain variation, only $35.2 \%$ was due to fixed effects, with $10.8 \%$ accounted by bite mass and its interactions. Concomitant experiments showed that sward structure (first with sward height and the second with tussock cover) does determine bite mass and short-term intake rate in the complex native grasslands we studied. Yet, other temporal varying components of monthly gain not correlated with bite mass, temperature or wind, added most of the observed variation in monthly animal performance. Part of the model failure to account for variation in performance may be related to a significant and temporally variable grazing of tussocks. We used a bite mass model that assumed no tussock grazing. In light of these results and a parallel experiment, we conclude that tussock grazing must be incorporated in future versions of the model.
\end{abstract}

Additional keywords: average daily gain, bite mass, intake rate, native grasslands, sward structure.

Received 2 May 2014, accepted 3 October 2014, published online 5 February 2015

\section{Introduction}

Grazing is the process by which herbivores feed on grasslands. They face a complex challenging nutritional environment, and exploit it by a series of nested processes that include bite formation and gathering (Laca 2008). In a seminal paper, Senft et al. (1987) stated that grazing decisions by which grazing animals interact with forage resources define spatial and temporal scales of foraging. These scales range from bite to home range, and biotic and abiotic factors influence grazing in every scale by different cause-effect relationships (Bailey et al. 1996).

Bite is the pivotal scale by which herbivores directly interact with forage resources (sensu tissue removal). This scale controls instantaneous intake rate when rates of food encounter are not constraining (Fortin 2006). In such a situation, bite mass is usually correlated with forage mass and sward surface height, defining the asymptotic relationship between forage mass and intake rate in grasslands (Carvalho 2013). Bite mass drives intake 
rate because large bites require less cropping time per unit food ingested (Shipley 2007). Although not mutually exclusive, bite gathering and chewing are competing events (Laca et al. 1994). By these mechanisms, bite scale of foraging is known to scale up and drive habitat segregation and migration of large herbivores across landscapes (Shipley 2007).

In homogeneous swards, daily forage intake models recognise sward factors that restrict intake at bite scale on the short-term (Delagarde et al. 2011; Gregorini et al. 2013; Mezzalira et al. 2014). However, there is less evidence regarding heterogeneous swards. Floristic and functional diverse foraging environments allow bite structural types of different plant life forms and architecture. Even if animals could gather only large bites, they do not, and bite mass varies for a same forage mass. For example, growing heifer performs 22 different bite types among more than 60 plant species when grazing heterogeneous swards; bite masses ranging from 0.01 to $4.025 \mathrm{~g}$ DM (Carvalho 2013). Registered bite masses from sheep and goats on native grasslands range from 0.03 to $2.0 \mathrm{~g}$ DM (Agreil et al. 2006). Bite diversity is rarely discussed as a requirement to foraging (see bite stabilisation feeding strategy discussed by Agreil et al. 2006). However, there is evidence that diversity in bite types results in average bite masses higher than in the situation where diversity is low (e.g. moderate grazing intensity vs high grazing intensity). Hence, it seems reasonable to suppose that animal performance responds positively to bite type diversity.

Considering grazing intake models, there are two general approaches usually assumed. Models derived from the concept of optimal foraging theory based on natural selection and ecological sense, and models based on sets of factors controlling diet selection and intake (Dove 1996). The second is the most popular for intensive agricultural systems and can provide predictive tools for 'eating to requirements' approach (Yearsley et al. 2001). However, these mechanisms that determine grazing behaviour and herbage intake are less certain at heterogeneous sward conditions. Nevertheless, considering the complexity of the mechanisms involved in grazing, it is doubtful where long-term processes (e.g. animal performance) can be deduced from integration of short-term processes (e.g. bites, intake rate in a meal). In fact, literature is scarce considering datasets fitted for linking short-term scale of biting to long-term outputs as animal performance (Agreil et al. 2006). Hence, we addressed the question on how grazing behaviour in short-term scales (bite) would predict animal outputs (daily gain) at long-term scales so as to guide sward management targets. We examined the ability of sequential models that included animal and sward parameters to predict the average daily gain of cattle in a long-term experiment on grasslands with heterogeneous sward structures. Because most processes constraining animal responses at lower spatio-temporal levels affect animal performance (Carvalho 2013), we hypothesised that bite mass would be an accurate predictor for average daily gain and should be considered to define sward targets in management for grasslands and heterogeneous sward structure.

\section{Materials and methods}

\section{Long-term experiment}

\section{Location, treatments and experimental design}

The study site was located at Federal University of Rio Grande do Sul Experimental Farm, Eldorado do Sul, Brazil $\left(30^{\circ} 05^{\prime} 27^{\prime \prime} \mathrm{S}, 51^{\circ} 40^{\prime} 18^{\prime \prime} \mathrm{W}\right)$. This long-term study was initiated in 1986 and encompasses an area of 64 ha of native grasslands called 'Campos Sulinos' (Bilenca and Miñaro 2004), where $\mathrm{C} 4$ grasses predominate. Pampa biome is part of the Campos Sulinos (IBGE 2004). Da Trindade et al. (2012) described the vegetation in the experimental area as a bimodal height structure consisting of a mosaic of short (inter-tussock) and tall (tussock) grasses. Inter-tussock areas are predominantly composed of Paspalum, Axonopus, Piptochaetium and Coelorachis genera. Tussocks are mainly composed of Aristida, Eryngium, Andropogon, Baccharis and Vernonia genera, which increase with decreasing grazing pressure. The climate is subtropical humid (Cfa classification, Köppen), with annual precipitation of $1440 \mathrm{~mm}$, well distributed throughout the year; June is the wettest month $(168.2 \mathrm{~mm})$, and December is the driest $(97.7 \mathrm{~mm})$. For the purposes of the present paper, we used experimental data from 2004 to 2013.

The experiment was conducted under continuous stocking with young beef cattle. Daily forage allowances (FA) of 4, 8 , 12 , and $16 \mathrm{~kg}$ DM per $100 \mathrm{~kg}$ of the animal's bodyweight $(\mathrm{kg} \mathrm{DM} /$ $100 \mathrm{~kg} \mathrm{BW}$ or simply \%BW) were chosen to create contrasting grazing intensities, maintained throughout the year by monthly adjustments of a number of animals based on forage mass present. In addition, during spring, three treatments with variable FA were used: $8-12 \% \mathrm{BW}, 12-8 \% \mathrm{BW}$ and $16-12 \%$ $\mathrm{BW}$ (where the first number is the FA in spring and the second is the FA in other seasons). Da Trindade et al. (2012) provided details about stocking rate adjustments and pasture evaluation. There were no other anthropogenic interventions in the experimental units beyond grazing intensity adjustments. The experiment is arranged in a randomised block design with two replicates. Differences in soil type were determinant for blocking criteria. The experimental unit is paddock; paddocks vary in area from 3.0 to 5.2 ha and present a slightly undulating relief.

Monthly mean data on temperature, precipitation and wind speed were obtained from a nearby $(\sim 1 \mathrm{~km})$ meteorological station. Between 2004 and 2013, the values (average \pm standard deviation) of temperature, annual precipitation and wind speed were $19.1 \pm 4.1^{\circ} \mathrm{C}, 1490 \pm 898 \mathrm{~mm}$ and $1.6 \pm$ $0.6 \mathrm{~m} / \mathrm{s}$, respectively.

\section{Sward measurements}

Sward characteristics were evaluated every 28 days. Forage mass $(\mathrm{kg} \mathrm{DM} / \mathrm{ha})$ in the inter-tussock area was determined by a double-sampling technique (Da Trindade et al. 2012), using a calibration of visual estimates with clipped samples. A 0.5 by $0.5 \mathrm{~m}$ metal quadrat was randomly placed in 50 random locations in each paddock and moved to the closest intertussock area if it fell on a tussock. Proportion of paddock area covered by tussocks was estimated as the proportion of quadrats that fell on tussocks. Forage mass in the inter-tussock was visually estimated, and sward height was measured with a sward stick at five points inside each quadrat. Visually 
estimated forage mass was corrected using linear regressions between estimated and clipped forage mass from quadrats used to determine daily forage accumulation rate (DAR) as described below.

Forage accumulation rate was estimated every 28 days using three or four pairs of plots and grazing exclusion cages per paddock. At the beginning of each 28-day period, one plot of each pair was protected with the cage and the other was visually estimated and clipped to litter level. The plot protected at the beginning of the previous period was also clipped, but it was not used for visual estimation. Clipped forage was oven-dried at $65^{\circ} \mathrm{C}$ for $72 \mathrm{~h}$ and then weighed with a precision balance. We estimated DAR as the mass in the protected plot after 28 days of protection minus the mass in the paired unprotected plot after the same 28 days of exposure to grazing, divided by 28 days.

Forage allowance (FA, \%BW) was calculated as

$$
\mathrm{FA}=[(\mathrm{FM} / n+\mathrm{DAR}) / \mathrm{SR}] \times 100,
$$

where $n=$ number of days in each period between evaluations, $\mathrm{DAR}=$ daily $\mathrm{DM}$ accumulation rate $(\mathrm{kg} \mathrm{DM} / \mathrm{ha}), \mathrm{FM}=$ forage mass $(\mathrm{kg} \mathrm{DM})$ and $\mathrm{SR}=$ stocking rate $(\mathrm{kg} \mathrm{BW} / \mathrm{ha})$.

Daily forage disappearance per animal (FD, kg DM/animal) is an indicator of the forage harvest efficiency and it was calculated as

$$
\mathrm{FD}=\left(\mathrm{FM}_{t}-\mathrm{FM}_{t-1}+[\mathrm{DAR} \times n]\right) /(n a \times n),
$$

where $\mathrm{FM}_{t}=\mathrm{FM}(\mathrm{kg} \mathrm{DM})$ evaluated in the Period $t, \mathrm{FM}_{t-1}=\mathrm{FM}$ evaluated in the Period $t-1$ and $n a=$ number of animals.

\section{Animal measurements}

Experimental animals were crossbred (Bos taurus $\times$ Bos indicus) heifers $(244.8 \pm 39.0 \mathrm{~kg} \mathrm{BW})$. A new set of heifers was used every year. Average daily gain (ADG, kg/animal) was estimated by weighting three tester animals per paddock every 28 days. All animals were fasted from solids and liquids for $10 \mathrm{~h}$ before each weighting.

Tester animals were considered the animals that started each year. The other animals used to adjust the FA were considered to compose the stocking rate.

\section{Short-term experiments}

We tested the relationship between bite mass (g DM/bite) and short-term intake rate (g DM/min.kg BW) with protocols for the meal scale of foraging. All experiments were designed to minimise the effects of abiotic factors and digestive constrains, making intake rate the main currency. Abiotic factors were controlled by the use of small paddocks (no slope nor foci attractions). Digestive constrains were minimised by the duration of the grazing tests $(45 \mathrm{~min})$ and by the period of the day in which those tests were performed (beginning of the main daily meals, dusk and dawn).

Data from three linked experiments were integrated into our modelling approach. In Experiment 1, Gonçalves et al. (2009) determined the relationship between inter-tussock sward heights $(4,8,12$ and $16 \mathrm{~cm})$ on beef heifer intake rate in areas without tussocks. Bremm et al. (2012; Experiment 2) evaluated the effect of controlled tussock-cover treatments
$(0 \%, 25 \%, 50 \%$ and $75 \%)$. Finally, in Experiment 3, Neves (2012) quantified short-term intake rate in representative subareas of the main FA experiment $(4 \%, 8 \%, 12 \%$ and $16 \%$ BW). Data from these experiments were used to determine the relationship between bite mass and sward characteristics at the bite site, and between intake rate and bite mass, as well as to test the equation used to estimate bite mass described below.

\section{Factors explaining $A D G$}

We developed a conceptual model that focuses on the essential factors and processes involved in determining ADG, including direct and indirect causative factors (Fig. 1). The model includes short-term variables such as bite mass and sward surface height, and long-term variables such as forage disappearance, animal $\mathrm{BW}$ and $\mathrm{ADG}$, which integrate the effects of short-term conditions into secondary productivity.

On the basis of this conceptual model, we developed a mechanistic-empirical model to predict ADG, assuming bite mass as the main driving process. The model is static and spatial aspects are only implicitly considered, for example, through tussock cover. Mechanistic parts of the model are those links that result from mathematical relationships that need no estimated parameters. For example, intake rate is the product of bite mass and bite rate, and bite mass is the product of BA, bite depth and bulk density of the grazed sward canopy stratum.

The bite mass (BM, g DM/bite) was derived from bite volume (cylinder) and the sward bulk density $(\mathrm{BkD})$ in that volume, as follows:

$$
\mathrm{BM}=\mathrm{BA} \times(\mathrm{H} / 2) \times \mathrm{BkD},
$$

where $\mathrm{BA}=$ bite area $\left(\mathrm{cm}^{2}\right), \mathrm{H}=$ sward surface height $(\mathrm{cm})$ and $\mathrm{BkD}=$ bulk density $\left(\mathrm{g} / \mathrm{m}^{3}\right)$ of the top half of the sward canopy.

Bite depth was estimated as half of $\mathrm{H}$ (Cangiano et al. 2002; Carvalho 2013). BkD (g/m $\mathrm{m}^{3}$ ) was estimated with an empirical model developed with data from short-term experiments (Experiments 1 and 2; Gonçalves et al. 2009; Bremm et al. 2012) as follows. First, an exponential decline of bulk density with horizon height, modulated by total sward height, was fitted to average horizon bulk density, as follows:

$$
\begin{aligned}
\operatorname{Bulk} \operatorname{density}(\mathrm{h}, \mathrm{H})= & \beta_{0}+\beta_{1} \mathrm{e}^{-(\mathrm{h} \times(\mathrm{g} 0+\mathrm{g} 1 \times \mathrm{H}))} \\
& +\beta_{2} \mathrm{H}+\beta_{3} \mathrm{H} \mathrm{e}^{-\mathrm{h} \times(\mathrm{g} 0+\mathrm{g} 1 \times \mathrm{H}))},
\end{aligned}
$$

where $\mathrm{H}=$ total sward surface height, $\mathrm{h}=$ horizon height and the rest of the symbols are parameters that were estimated empirically $\left(R^{2}=0.52\right.$; $\left.\mathrm{RMSE}=50.8 ; n=69\right)$. Then, an equation to estimate average $\mathrm{BkD}$ was obtained by analytical integration of Eqn 4.

Bite area $\left(\mathrm{BA}, \mathrm{cm}^{2}\right)$ was estimated with an empirical model that includes effects of $\mathrm{H}$ and BkD (Baumont et al. 2004), and considered as an allometric relationship of the size of animal's dental arcade (DA) breadth (Illius and Gordon 1987). The BA was assumed as an asymptote positive function in relationship to $\mathrm{H}$ and an exponential negative effect in relationship to $\mathrm{BkD}$ (Laca et al. 1992): 


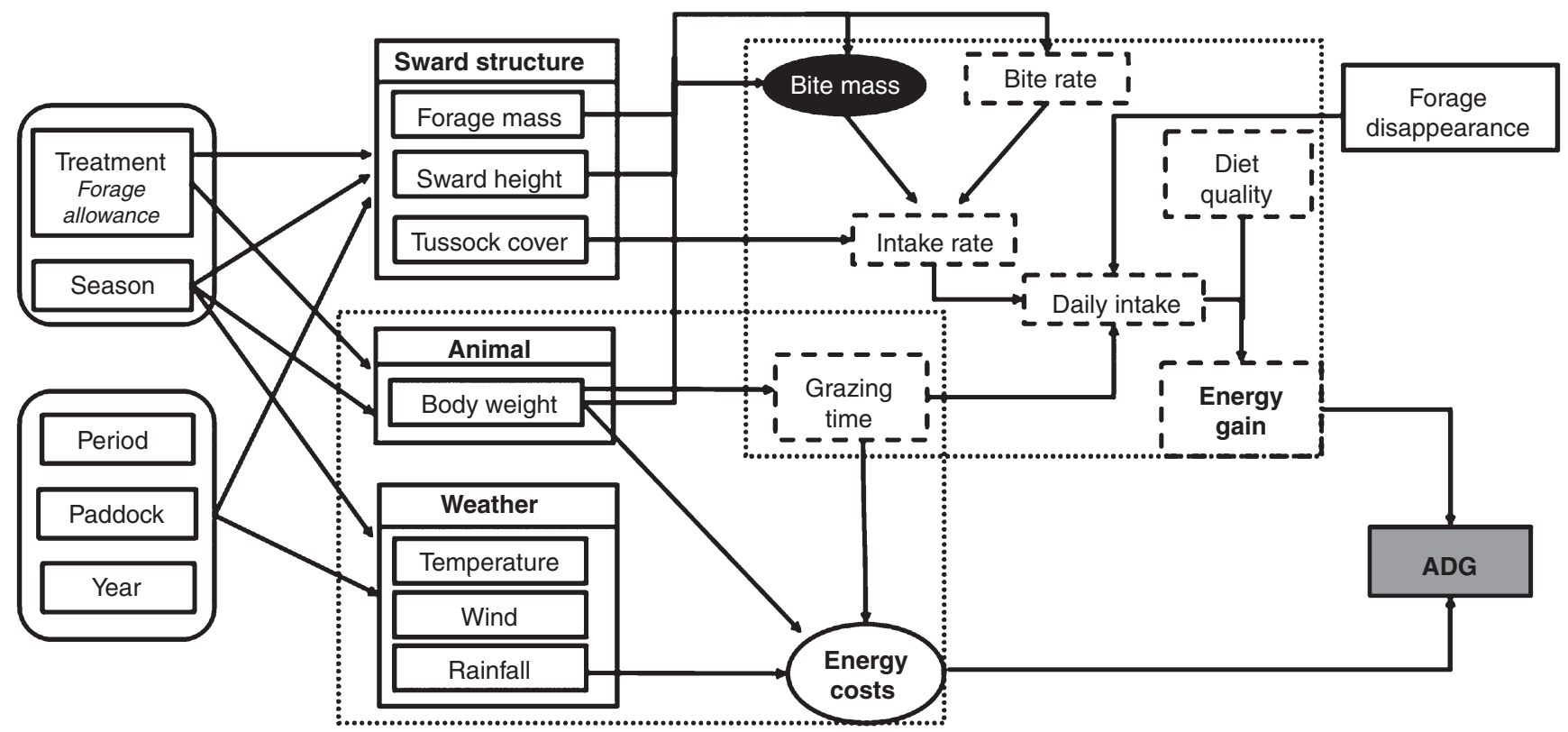

Fig. 1. Structure of the conceptual model. Solid boxes show measured variables, ellipses show the calculated variables, and dashed boxes show unmeasured variables. Dotted boxes group factors that determine energy gain or energy expenditures.

$$
\mathrm{BA}=2 \times \mathrm{DA}^{2}(1+50 / \mathrm{H})^{-1} \times \mathrm{e}^{(-0.3 \times(\mathrm{BkD}-1))},
$$

where DA = the animal's dental arcade breadth, $\mathrm{H}=$ sward surface height $(\mathrm{cm})$, and $\mathrm{BkD}=$ the bulk density of the grazed stratum of the sward canopy. DA breadth was calculated using the allometric equation published by Illius and Gordon (1987).

Energy cost to graze (EC, Mcal $/ \mathrm{kg}$ of $\mathrm{BW}$ ) included maintenance and energy expenditure during grazing (NRC 1996), assuming a daily DM intake of $2.5 \% \mathrm{BW}$ of a forage with $50 \%$ of total digestible nutrients, as follows:

$$
\begin{aligned}
\mathrm{EC}= & 0.077 \times \mathrm{BW}^{0.75}+(0.00216 \times 0.025 \times \mathrm{BW} \\
& +(0.05 /(\mathrm{FM} / 1000)+3)) \times(\mathrm{BW} / 4.184),
\end{aligned}
$$

where $\mathrm{BW}=$ animal $\mathrm{BW}(\mathrm{kg})$ and $\mathrm{FM}=\mathrm{FM}(\mathrm{kg} \mathrm{DM} / \mathrm{ha})$.

The overall model has three levels (Fig. 1). First, ADG is exclusively a response variable whose variance might be explained by variables in the second and third levels. In the second level, FM, H, FD, proportion of tussock cover, animal weight, average temperature, rainfall and wind speed act as predictors and responses. In the third level, nominal treatments, seasons, years, paddocks and months are exogenous and terminal explanatory variables. The model included random effects for grouping variables such as paddock, year, month within season and year, and the coefficient of BM over seasons and years. These random effects were identified variance in ADG that is not explained by any of the fixed effects, but that is associated with specific components of variation among measurements over space and time.

Because we are interested in estimating the importance of $\mathrm{BM}$ and proximate factors of $\mathrm{ADG}$, we established an a priori order of effects into the model, and tested these effects with sequential sum of squares (Type I SS). BM was given priority over other variables such as tussock cover, FM and H. Animal weight, average temperature and wind speed had lower priority as potential causative factors. Nominal FA treatments and seasons had the lowest priority, as they are not direct causative factors, but must act through other proximate factors that determine ADG, such as energy gain and energy costs.

Model development for ADG proceeded by simplification of a full model. The full model, expressed as a linear mixed-effects model equation for the linear mixed-effects models (lmer) function of the lme4 package (Bates et al. 2014) was

$$
\begin{aligned}
& \text { sADG } \sim \text { sBM + sBM.sq + sBM.qb }+ \text { spTussock }+ \text { sFM } \\
& + \text { sFD }+ \text { sH }+ \text { poly }(\text { sAnimalBW }, 2)+\text { sTavg }+ \text { sWind } \\
& + \text { sCost }+ \text { Season }+ \text { sBM }: \text { Season }+ \text { sBM.sq: Season } \\
& + \text { FA }+ \text { FA }: \text { Season }+(1 \mid \text { year })+(1 \mid \text { paddock }) \\
& +(1 \mid \text { ssn.yr })+(1 \mid \text { mo.ssn.yr }),
\end{aligned}
$$

where all continuous variables were standardised, FA = the nominal FA as a categorical predictor, and ssn.yr and mo.ssn. $\mathrm{yr}=$ composite variables to represent groupings of seasons within years and months within seasons within years, respectively. First, non-significant random effects were identified by likelihood ratio tests and removed. Then, fixed effects were iteratively simplified by removing the last nonsignificant effect $(P>0.05$ by sequential sum of squares) not involved in a significant interaction (Fig. 2). Statistical analyses were conducted using R 3.0.1 (R Development Core Team 2014).

\section{Results}

\section{Short-term experiments}

Bite mass predicted by Eqn 3 was closely related to BM observed when sward characteristics were measured in areas grazed and corrected for tussock cover $\left(y=0.08+0.83 x 1-0.30 \times 2, R^{2}=0.71\right.$, RMSE $=0.08, P<0.001)$, where $y$ is observed BM, $x l$ is calculated $\mathrm{BM}$, and $x 2$ is proportion of tussocks in the pasture. 
Bite mass determined most of the variation in instantaneous intake rate when allowing for differences of intercept and slope between the short-term Experiments 1 and $2\left(R^{2}=0.96\right.$, $P<0.001)$. The differences in slope and intercept were consistent with the fact that heifers were fasted in Experiment 1, but not in Experiment 2. $\mathrm{H}$ and tussock cover were good predictors of intake rate (Fig. 2). Intake rate exhibited a quadratic response to both predictors, as well as effects of experiment on the slopes.

\section{Prediction of ADG of heterogeneous swards}

A summary of the main variables used in the model is presented in Table 1. The final model for ADG was

$$
\begin{aligned}
& \text { sADG } \sim \text { sBM + sBM.sq + BM.qb + sFD + sTavg } \\
& \text { + Season + sBM: Season + sBM.sq: Season + FA } \\
& \text { + FA : Season + (1|mo.ssn.yr }) .
\end{aligned}
$$

Forage allowance treatments, seasons, and their interaction (distal explanatory variables), together with random effects due

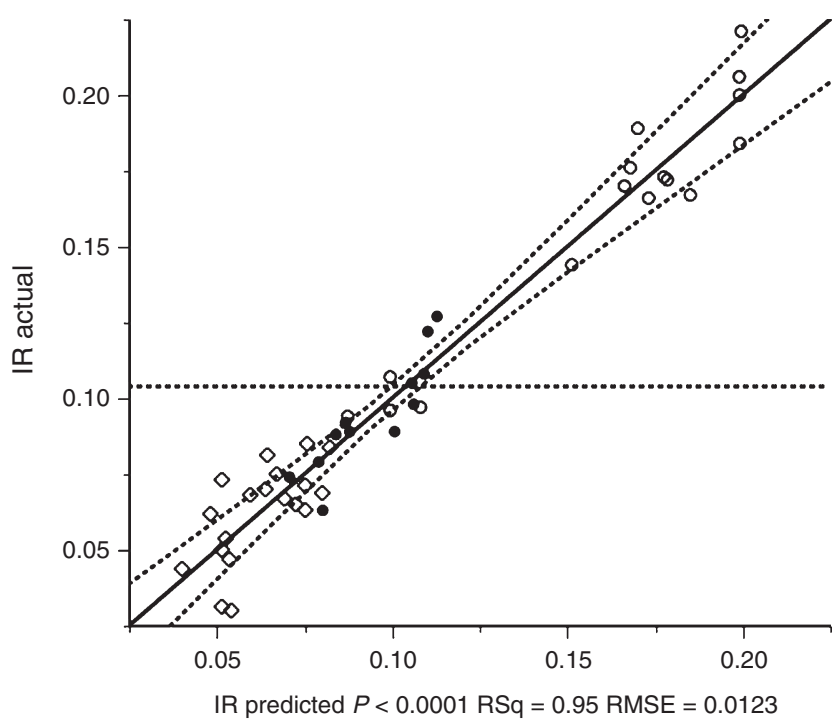

Fig. 2. Short-term intake rate (IR; g DM/min.kg bodyweight) by heifers as explained by sward height and tussock cover in native grasslands $\left(R^{2}=0.95\right.$, RMSE $\left.=0.012, P<0.0001, n=47\right)$. to the combination of month within year, accounted for a total of $77.9 \%$ of the ADG variation. This $77.9 \%$ includes $35.2 \%$ due to fixed effects, with $15.8 \%$ attributable to direct effects of season. BM and its interactions with season accounted for $10.8 \%$ of the variation of ADG. FA and its interaction with season explained $2.6 \%$ of the variation in ADG.

This selected and final model includes effects of BM and FA on ADG, which means that FA treatments and season had effects $(2.6 \%$ of the variation) on ADG through unmeasured variables not correlated with the measured proximate causative variables (Fig. 3). Season explained the most variation in ADG, even after BM and FA were given priority in the sequential sum of squares.

In a separate model, $87 \%$ of the variation in ADG was explained by the combination of FA, month and year. This indicates that variation among paddocks and measurement errors were relatively small (13\%). A large proportion of the variation in $\mathrm{ADG}, \mathrm{H}$ and $\mathrm{BM}$ was therefore 'structured' in the sense that it was highly correlated among treatments and paddocks over time, with little variation among paddocks or treatments for a given month and year. Although total and structured variation of $\mathrm{ADG}$ was related to $\mathrm{H}, \mathrm{BM}$ and other mechanistically explanatory (proximate) variables, most of the structured variance in ADG (42.7\%) was associated with the random effects of months within years.

As hypothesised, neither FM nor $\mathrm{H}$ had effects on ADG beyond that explained by BM. FD had a minor but significant role, explaining $1.5 \%$ of the variation in ADG.

Forage allowance affected ADG directly and indirectly through $H$. The small but significant variation of ADG explained directly by FA and its interaction with season, after correcting for BM (2.6\%), was mostly due to the fact that the lowest FA treatment had lower ADG than the rest of the treatments, particularly in fall and spring (Fig. 4). The indirect effect of FA took place through $\mathrm{H}$ and the effect of $\mathrm{H}$ on $\mathrm{BM}$.

Forage allowance treatments explained about half of the variation in the components of $\mathrm{BM}(48.5 \%$ of the variation in $\mathrm{FM}$ and $52.9 \%$ of the variance in $\mathrm{H}$ were explained by treatments). BM was modelled as a deterministic function of $\mathrm{BA}$ and sward BkD. In turn, BA was determined by DA width, which depended on animal weight, and $\mathrm{BkD}$ of the grazed stratum was a function of FM. Therefore, $\mathrm{H}$ and FM explained all of the variation in BM, with the majority of the variation being explained by $\mathrm{H}(86.4 \%)$.

Table 1. Sward and animal data (average values \pm standard deviation) used in predicted models $(n=590)$

\begin{tabular}{|c|c|c|c|c|c|c|c|}
\hline Variable & \multicolumn{7}{|c|}{ Treatment (forage allowance, $\mathrm{kg} \mathrm{DM} / 100 \mathrm{~kg}$ bodyweight) } \\
\hline AFA & $5.6 \pm 2.3$ & $11.7 \pm 4.8$ & $19.3 \pm 6.7$ & $26.2 \pm 7.8$ & $16.8 \pm 6.0$ & $15.2 \pm 4.9$ & $21.7 \pm 8.0$ \\
\hline SH & $4.0 \pm 1.0$ & $5.4 \pm 1.4$ & $7.7 \pm 2.0$ & $8.9 \pm 2.2$ & $6.9 \pm 1.7$ & $6.7 \pm 2.0$ & $8.8 \pm 2.2$ \\
\hline $\mathrm{TC}$ & $1.9 \pm 2.0$ & $23.6 \pm 6.4$ & $35.2 \pm 7.4$ & $41.4 \pm 11.9$ & $27.4 \pm 9.0$ & $34.0 \pm 11.8$ & $37.6 \pm 9.4$ \\
\hline FD & $-5.3 \pm 15.3$ & $10.4 \pm 12.9$ & $13.5 \pm 18.4$ & $17.9 \pm 24.6$ & $3.6 \pm 16.8$ & $6.1 \pm 15.1$ & $14.7 \pm 19.2$ \\
\hline ADG & $0.051 \pm 0.395$ & $0.192 \pm 0.323$ & $0.224 \pm 0.327$ & $0.234 \pm 0.306$ & $0.239 \pm 0.303$ & $0.211 \pm 0.309$ & $0.252 \pm 0.327$ \\
\hline
\end{tabular}

$\mathrm{AFA}$, actual forage allowance $(\mathrm{kg} \mathrm{DM} / 100 \mathrm{~kg}$ bodyweight); $\mathrm{SH}$, sward height $(\mathrm{cm})$; FM, forage mass $(\mathrm{kg} \mathrm{DM} / \mathrm{ha})$; TC, tussock cover (\%); FD, forage disappearance (kg DM/an.day); ADG, average daily gain ( $\mathrm{kg} /$ day) 


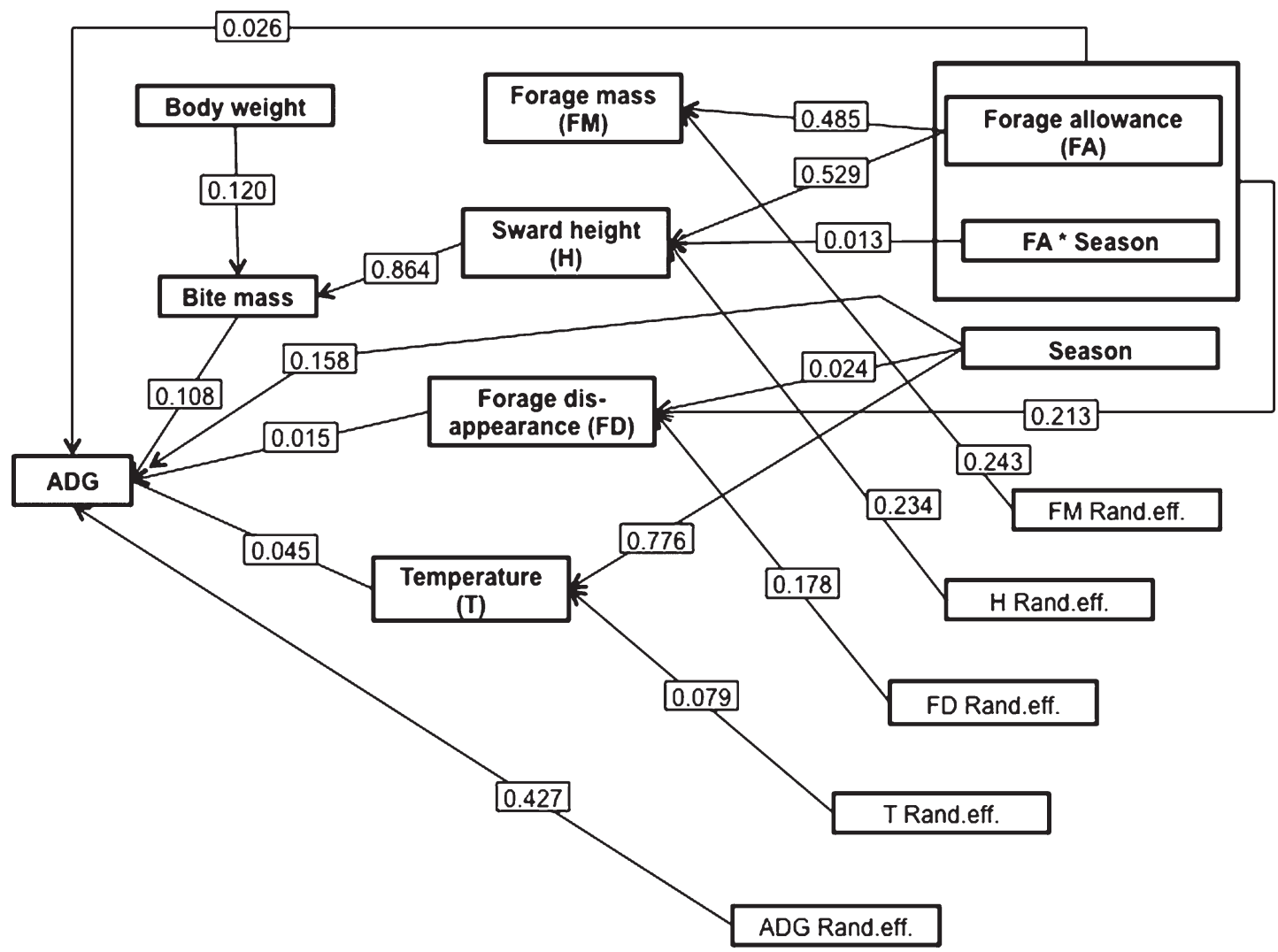

Fig. 3. Explanatory effects in the predicted model for average daily gain. Numbers in boxes represent the proportion of the variance of the variable at the head of each arrow explained by the variable at the tail of the arrow. Only significant effects $>0.01$ are shown for simplicity.

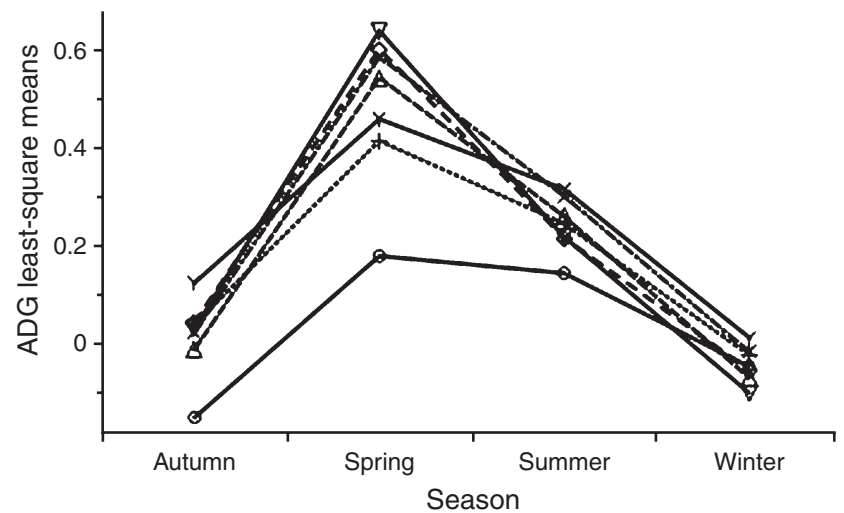

Fig. 4. Effects of forage allowance and season on animal performance (ADG is average daily gain in $\mathrm{kg}$ /day). Least-square means of ADG are corrected for the effect of bite mass. $(\bigcirc, 4 \% \mathrm{BW}+,+8 \% \mathrm{BW} ; \diamond, 12 \% \mathrm{BW}$; $\times, 16 \% \mathrm{BW} ; \triangle, 12-8 \% \mathrm{BW} \vee, 8-12 \mathrm{BW} ; \square, 16-12 \mathrm{BW})$.

\section{Discussion}

Our initial hypotheses that BM and intake rate are sufficient integrators of all relevant foraging environment characteristics determining animal performance is not supported by this analysis. What parts of the hypothesis are incorrect? To answer this question, we identify the essential components of the hypothesis and discuss each in turn.
Our hypothesis is largely based on the idea that in complex and heterogeneous foraging environments, animals always face a trade-off between intake rate and diet quality (Bergman et al. 2001; Carvalho 2013), where improvement of nutritional conditions results from greater availability of forage with high nutritive value. Greater availability of forages with high feeding value (sward structure - Carvalho 2013), should lead to diet of greater nutritive value, but also to greater intake rate, and potentially shorter grazing time per day.

Given that the conceptual model is well established and that it includes causative factors such as grazing time and diet nutritive value not directly linked to short-term characteristics of the grazing process, our hypothesis requires that changes in factors such as temperature and resulting changes in energetic costs be reflected in measureable short-term behaviour. For example, bite rate for a given BM might be increased when high temperatures limit grazing time. In our model, short-term responses to large-scale factors would be captured in direct effects of the large-scale factors and interactions with BM, because we assumed a constant relationship between BM and sward structure. Direct effects of large-scale factors were detected for FD, temperature, season and FA. Notably, $15.8 \%$ of the total and $44.9 \%$ of the explained ADG variation was caused by differences among seasons through mechanisms not involving $\mathrm{H}, \mathrm{FM}$, animal weight or average temperature. Yet, all of them together explain a relatively small part of the variance in $\mathrm{ADG}$. 
A large percentage $(42.7 \%)$ of this total variance was a random effect of month within year not caused by paddock or measurement variance, because the pooled variance among paddocks within month and year was just $12.8 \%$ of the total. We interpret this to mean that there are other unmeasured variables unrelated to measured explanatory variables that affected ADG in all paddocks in a similar way, and that changed from month to month in a manner not explained by seasons. Identification of these variables and the proximate components of ADG through which these variables act will be the subject of further research.

The main hypothesis also assumes that BM is mostly determined by sward canopy structure and mass at the bite locations, and that intake rate is determined chiefly by BM. The concomitant short-term experiments confirm the effects of sward canopy structure and BM on intake rate that have been corroborated in many studies (e.g. Soder et al. 2009; Amaral et al. 2013). BM fully accounted for the variation in ADG explained by $\mathrm{H}$ and FM, because these two sward variables had no explanatory contribution beyond BM, and fell out of the model when BM was included with priority. However, $\mathrm{BM}$ and associated effects (linear, quadratic, cubic effects and interactions) account for only $10.8 \%$ of the total and $35.2 \%$ of the explained variance in ADG.

Overall, the essential components of the main hypothesis appear to be qualitatively correct, but the statistical model we used failed to explain a large proportion of the variation in ADG. In particular, why did BM contribute so little to the variation in ADG? Below, we discuss evidence towards a series of explanatory factors that could be acting in multiple combinations.

\section{$B M$ variation}

First, BM may not have varied much or it may have varied within a range of values where intake rate was not responsive due to being near the maximum determined by ingestive processing constraints. Actually, BM in the main experiment ranged from 0.09 to $0.92 \mathrm{~g}$, which is the typical range where intake rate responds strongly to $\mathrm{BM}$ (Fig. 5). The strong response of intake rate to $\mathrm{BM}$ was confirmed by short-term experiments conducted in the same grasslands (Gonçalves et al. 2009; Bremm et al. 2012; Neves 2012).

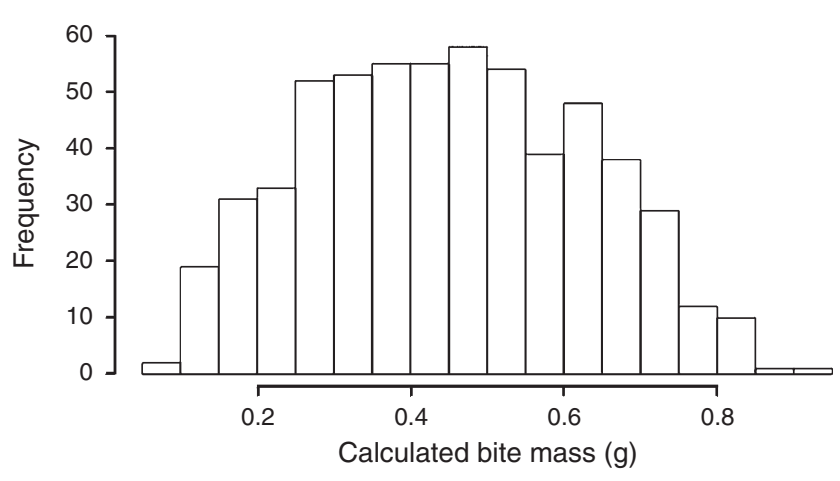

Fig. 5. Histogram of bite mass calculated using Eqn 3 (see text) and data for forage mass and sward height from the main experiment.
Second, we should consider the fact that BM was calculated using relationships between BM and sward characteristics at the location of the bites, whereas for input, we used average sward characteristics measured in the preferred inter-tussock stratum. Animals may have selected areas for grazing that departed significantly from the average for the inter-tussock stratum. Novel results by Bonnet et al. (2015) confirmed that heifers take a significant proportion of bites from tussocks ( 30\% of bites), and these proportions show variation over time. The assumption of non-selective grazing exclusively within the inter-tussock is not a failure of our main hypothesis, but of our original conceptual model used to test the hypothesis.

A better conceptual model that includes tussock grazing is also supported by previous results. As FAs increases, intertussock height increases proportionally less than does tussock cover. Thus, the forage selection process becomes more complex and motivates more tussock grazing. Bremm et al. (2012) found that when the non-preferred tussock reaches a threshold cover of $\sim 35 \%$, the animals sacrifice food nutritive value for faster cropping, taking larger bites in the less-preferred item more frequently. This behaviour is qualitatively consistent with a trade-off between 'quality' and quantity of diet that might reflect a tendency to optimise the diet selectivity (Fortin et al. 2002; Searle et al. 2007).

\section{Digestive constrains and diet quality}

Diet quality is a determinant of energy intake, but it was not directly measured or modelled. In such heterogeneous swards, diet nutritive value can vary significantly over time. When diet quality is low and animals have little opportunity to change it through increased selectivity, grazing time should be the main variable explaining variation in $\mathrm{ADG}$, whereas intake rate and $\mathrm{BM}$ would remain relatively unchanged as foraging conditions change.

Therefore, an alternative explanation for the weak association between intake rate and $\mathrm{ADG}$ is that digestive constraints may have obliterated the effects of $\mathrm{BM}$ in intake rate through compensatory changes in grazing time. This rationale implies that the range of diet 'qualities' achieved was such that total daily intake was strongly limited by the need to ruminate and digest forage. It would also imply that animals had little opportunity or lacked the ability to trade intake rate for diet nutritive value. Mezzalira et al. (2012) and Da Trindade et al. (2012) evaluated the ingestive behaviour of heifers in the same long-term experiment and registered a variation in grazing time from 513 to $638 \mathrm{~min}$, described by a quadratic relationship between FA and grazing time. In an adapted model using data from these two studies, grazing time was significantly affected by inter-tussock surface height and tussock cover $\left(y=532.08+9.85 x+0.37 x^{2}-3.57 z+0.18 z^{2}\right.$, $R^{2}=0.6868$, RMSE $=42.6, P=0.006, n=29, x=$ height,$z=$ tussock cover), which indicates that, indeed, grazing time probably changed significantly over the study and in ways not accounted for by the statistical model we used.

As mentioned before, preliminary observations indicated that animals do explore a potential dimension of diet nutritive value by changing the proportion of bites taken from tussocks instead of short inter-tussock areas. Thus, we surmise that in the 
majority of the situations animals had already reached a level of selectivity beyond which no further trade-off was profitable or possible. This view is consistent with the fact that season had an important effect on ADG in a pattern consistent with forage nutritive value. Seasons that had higher ADG (after correcting for BM, FD and temperature) also had better forage nutritional value. Neutral detergent fibre content of the grazed inter-tussock horizon varied from $71.5 \%$ to $77.6 \%$ neutral detergent fibre as FA increased from $4 \%$ to $16 \%$ FA. Crude protein followed a consistent pattern, decreasing from $12.0 \%$ to $9.5 \%$ as FA increased from $4 \%$ to $16 \% \mathrm{FA}$, thus, reinforcing the rationale that diet nutritive value was a variable associated with season, but not with FA, that affected ADG.

\section{Energy}

Energy costs to graze were indirectly estimated in the model and could affect net energy available for gain if grazing time modifies energy cost differently from model predictions. The energy required to just crop forage is an insignificant part of the animal requirements (Stobbs 1975), but the energy cost of activities associated with grazing (search, selection and manipulation) has been estimated to range between $25 \%$ and $50 \%$ of their daily energy requirements for maintenance of body mass (Osuji 1974). For example, Murray (1991) found that total heat production could range from 15 to more than 30 $\mathrm{MJ} /$ day as selectivity and search costs per unit intake increased. High levels of selectivity lead to large search and walking energy costs per day. In addition, the potential effects of a variable partition of net energy intake between muscle and fat gain were not contemplated in the model and may have contributed to the low proportion of variation explained.

In summary, the fixed effects of the model explained only $35.2 \%$ of ADG variance. FA treatments, either directly or indirectly, explained less than $10 \%$ of the variation in animal gain. Season was the most important 'known' factor affecting ADG. A large amount of variation in ADG was associated with random effects, and thus, was caused by mechanisms not contemplated in the measured variables or other variables associated with treatments or seasons. BM accounted for $10.8 \%$ of the total variance in $\mathrm{ADG}$, and it was driven by inter-tussock height.

Therefore, simple scaling up of effects of BM and intake rate was only partially consistent with long-term measurements of animal performance. Intake rate was adequately predicted by sward structure at the areas grazed in the short term, even in heterogeneous swards. Modelling and understanding of longterm ADG, however, requires temporal integration of measurements of intake rate and diet nutritive value at the bite level instead of multiplication of average values of each component. The present results exposed limitations in the link between sward canopy structure and animal performance, and suggested key variables to monitor grasslands towards the creation of suitable foraging environments for grazing animals.

\section{Conclusions}

We tested the hypothesis that variation in daily liveweight gain measured over months can be largely explained by changes in variation in instantaneous intake rate and BM. Our hypothesis was not supported by this analysis. Stocking (i.e. FA) treatments and seasons had significant effects not explained by differences in BM or intake rate. Although the model explained $77.9 \%$ of variation in liveweight gain, only $35.2 \%$ was due to fixed effects, with a significant $10.8 \%$ accounted for by BM and its interactions. This implies that there must have been significant patterns of change in diet nutritive value over seasons and treatments that were not reflected in or associated with changes in BM. Part of the failure to account for variation in performance may be related to a significant and temporally variable grazing of tussocks, which is a factor not included in the model we used to estimate BM and intake rate. Overall, our results indicated that more precise understanding of the factors that determine most of the variation in daily liveweight gain will require more detailed estimation of both energy intake and energy expenditure.

\section{Acknowledgements}

This work was supported by grants from the Brazilian National Council for Scientific and Technological Development (CNPq), and partial supports from funding from the European Community's Seventh Framework Program (FP7/2007-2013) under the grant agreement no. 266018, and from FAPERGS (project no. 12/1362-6).

\section{References}

Agreil C, Meuret M, Fritz H (2006) Adjustment of feeding choices and intake by a ruminant foraging in varied and variable environments: new insights from continuous bite monitoring. In 'Feeding in domestic vertebrates: from structure to behaviour'. (Ed. V Bels) pp. 302-325. (CAB International: Wageningen, The Netherlands)

Amaral MF, Mezzalira JC, Bremm C, Da Trindade JK, Gibb MJ, Suñe RWM, Carvalho PCF (2013) Sward structure management for a maximum short-term intake rate in annual ryegrass. Grass and Forage Science 68, 271-277. doi:10.1111/j.1365-2494.2012.00898.x

Bailey DW, Gross JE, Laca EA, Rittenhouse LR, Coughenour MB, Swift DM, Sims PL (1996) Mechanisms that result in large herbivore grazing distribution patterns. Journal of Range Management 49, 386-400. doi:10.2307/4002919

Bates D, Maechler M, Bolker B, Walker S (2014) 'Lme4: linear mixedeffects models using Eigen and S4. R package version 1.1-6.' Available at http://CRAN.R-project.org/package=lme4 [Verified 25 April 2014]

Baumont R, Cohen-Salmon D, Prache S, Sauvant D (2004) A mechanistic model of intake and grazing behaviour in sheep integrating sward architecture and animal decisions. Animal Feed Science and Technology 112, 5-28. doi:10.1016/j.anifeedsci.2003.10.005

Bergman CM, Fryxell JM, Gates CC, Fortin D (2001) Ungulate foraging strategies: energy maximizing or time minimizing? Journal of Animal Ecology 70, 289-300. doi:10.1046/j.1365-2656.2001.00496.x

Bilenca D, Miñaro F (2004) 'Identificación de áreas valiosas de pastizal en las Pampas y Campos de Argentina, Uruguay y Sur de Brasil.' (Fundación vida Silvestre: BuenosAires, AR)

Bonnet OJF, Meuret M, Tischler MR, Cezimbra IM, Azambuja JCR, Carvalho PCF (2015) Continuous bite monitoring: a method to assess the foraging dynamics of herbivores in natural grazing conditions. Animal Production Science 55, 339-349. doi:10.1071/AN14540

Bremm C, Laca EA, Fonseca L, Mezzalira JC, Elejalde DAG, Gonda HL, Carvalho PCF (2012) Foraging behaviour of beef heifers and ewes in natural grasslands with distinct proportions of tussocks. Applied Animal Behaviour Science 141, 108-116. doi:10.1016/j.applanim.2012.08.008

Cangiano CA, Galli JR, Pece MA, Dichio L, Rozsypalek SH (2002) Effect of live weight and pasture height on cattle bite dimensions during progressive defoliation. Australian Journal of Agricultural Research 53, 541-549. doi:10.1071/AR99105 
Carvalho PCF (2013) Harry Stobbs memorial lecture: can grazing behaviour support innovations in grassland management? Tropical Grasslands Forrajes Tropicales 1, 137-155.

Da Trindade JK, Pinto CE, Neves FP, Mezzalira JC, Bremm C, Genro TCM, Tischler MR, Nabinger C, Gonda HL, Carvalho PCF (2012) Forage allowance as a target of grazing management: implications on grazing time and forage searching. Rangeland Ecology and Management 65, 382-393. doi:10.2111/REM-D-11-00204.1

Delagarde R, Faverdin P, Baratte C, Peyraud JL (2011) GrazeIn: a model of herbage intake and milk production for grazing dairy cows. 2. Prediction of intake under rotational and continuously stocked grazing management. Grass and Forage Science 66, 45-60. doi:10.1111/j.13652494.2010.00770.x

Dove H (1996) Constraints to the modelling of diet selection and intake in the grazing ruminant. Australian Journal of Agricultural Research 47, 257-275. doi:10.1071/AR9960257

Fortin D (2006) The allometry of plant spacing that regulates food intake rate in mammalian herbivores. Ecology 87, 1861-1866. doi:10.1890/ 0012-9658(2006)87[1861:TAOPST]2.0.CO;2

Fortin D, Fryxell JM, Pilote R (2002) The temporal scale of foraging decisions in bison. Ecology 83, 970-982. doi:10.1890/0012-9658 (2002)083[0970:TTSOFD]2.0.CO;2

Gonçalves EN, Carvalho PCF, Kunrath TR, Carassai IJ, Bremm C, Fischer V (2009) Relações planta-animal em ambiente pastoril heterogêneo: processo de ingestão de forragem. Brazilian Journal of Animal Science 38, 1655-1662. [In Portuguese]

Gregorini P, Minnee EM, Griffiths W, Lee JM (2013) Dairy cows increase ingestive mastication and reduce ruminative chewing when grazing chicory and plantain. Journal of Dairy Science 96, 7798-7805. doi:10.3168/jds.2013-6953

IBGE (Instituto Brasileiro de Geografia e Estatística) (2004) 'Mapa da vegetação do Brasil e Mapa de Biomas do Brasil.' Available at www. ibge.gov.br/home/geociencias/default_prod.shtm\#USO [Verified 4 April 2014]

Illius AW, Gordon IJ (1987) The allometry of food intake in grazing ruminants. Journal of Applied Ecology 56, 989-999. doi:10.2307/4961

Laca EA (2008) Foraging in a heterogeneous environment: intake and diet selection. In 'Resource ecology: spatial and temporal dynamics of foraging'. (Ed. V Bels) pp. 81-100. (CAB International: Wageningen, The Netherlands)

Laca EA, Ungar ED, Seligman N, Demment MW (1992) Effects of sward height and bulk density on bite dimensions of cattle grazing homogeneous swards. Grass and Forage Science 47, 91-102. doi:10.1111/j.1365-2494.1992.tb02251.x
Laca EA, Ungar ED, Demment MW (1994) Mechanisms of handling time and intake rate of a large mammalian grazer. Applied Animal Behaviour Science 39, 3-19. doi:10.1016/0168-1591(94)90011-6

Mezzalira JC, Bremm C, Da Trindade JK, Nabinger C, Carvalho PCF (2012) The ingestive behaviour of cattle in large-scale and its application to pasture management in heterogeneous pastoral environments. Journal of Agricultural Science \& Technology A 2, 909-916.

Mezzalira JC, Fonseca L, Bremm C, Cangiano C, Gonda HL, Carvalho PCF, Laca EA (2014) Behavioural mechanisms of intake rate by heifers grazing swards of contrasting structures. Applied Animal Behaviour Science 153, 1-9. doi:10.1016/j.applanim.2013.12.014

Murray MG (1991) Maximizing energy retention in grazing ruminants. Journal of Animal Ecology 60, 1029-1045. doi:10.2307/5429

Neves FP (2012) Oferta de forragem em pastagem natural: estrutura de pasto e taxa de ingestão de novilhas de corte. PhD Thesis, Federal University of Rio Grande do Sul, Brazil.

NRC (1996) 'National Research Council: nutrient requeriment of beef cattle.' 7 edn. (National Academy Press: Washington, DC)

Osuji PI (1974) The physiology of eating and the energy expenditure of the ruminant at pasture. Journal of Range Management 27, 437-443. doi: $10.2307 / 3896717$

R Development Core Team (2014) 'R: a language and environment for statistical computing.' (R Foundation for Statistical Computing: Vienna) Available at http://www.R-project.org/ [Verified 25 April 2014]

Searle KR, Hobbs NT, Gordon IJ (2007) It's the 'foodscape', not the landscape: using foraging behavior to make functional assessments of landscape condition. Israel Journal of Ecology \& Evolution 53, 297-316. doi:10.1560/IJEE.53.3.297

Senft RL, Coughenour MB, Bailey DW, Rittenhouse LR, Sala OE, Swift DM (1987) Large herbivore foraging and ecological hierarchies. Bioscience 37, 789-799. doi: $10.2307 / 1310545$

Shipley LA (2007) The influence of bite size on foraging at larger spatial and temporal scales by mammalian herbivores. Oikos 116, 1964-1974. doi:10.1111/j.2007.0030-1299.15974.x

Soder KJ, Sanderson MA, Gregorini P, Orr RJ, Rubano MD, Rook AJ (2009) Relationship of bite mass of cattle to sward structure of four temperate grasses in short-term grazing sessions. Grass and Forage Science 64, 421-431. doi:10.1111/j.1365-2494.2009.00710.x

Stobbs TH (1975) A comparison of zulu sorghum, bulrush millet and white panicum in terms of yield, forage quality and milk production. Australian Journal of Experimental Agriculture and Animal Husbandry 15, 211-218. doi:10.1071/EA9750211

Yearsley J, Tolkamp BJ, Illius AW (2001) Theoretical developments in the study and prediction of food intake. The Proceedings of the Nutrition Society 60, 145-156. doi:10.1079/PNS200062 